\title{
The Marine Protist Foraminifera
}

\section{Ishita D*}

Department of Geology, University of Calcutta, Kolkata, India

Editorial

Volume 3 Issue 1

Received Date: March 21, 2020

*Corresponding author: Ishita Das, Department of Geology, University of Calcutta, Kolkata, India, Email: ishita.mishtu@gmail.com

Published Date: June 02, 2020
The marine protist foraminifera have become a very important tool in palaeoenvironmental analysis. Foraminifera are organisms belonging to a class of amoeboid protists that are characterized by streaming granular ectoplasm for catching prey and they are commonly protected by an external shell. The external shell can be made up of varied material although the most common material is calcium carbonate. Some species have an agglutinated test where the organism constructs its test or shell from the sediment particles surrounding it. Foraminifera usually have two types of life habits - benthic or planktic. The benthic foraminifera may adapt to live on sediment-water interface (epifaunal) or in the sediment at various depths (infaunal). A number of benthic foraminiferal families have infaunal representatives, including Buliminidae, Uvigerinidae, Bolivinidae and Nodosaridae. These foraminifera tolerate different levels of oxygenation as well as incorporate different proportions of trace elements and consequently the proportion of epifaunal and infaunal foraminiferal morphotypes are useful in estimation of the degree of oxygenation as well as palaeoclimate interpretations. The living infaunal assemblage can be studied directly in the field but proxies need to be generated to know the infaunal microhabitat of the fossil species.

Geochemical proxies may be reliable indicator of oxygenation levels. The carbon isotopic ratio $(\delta 13 \mathrm{C})$ of the dissolved inorganic carbon (DIC) also decreases below the sediment water interface. Similarly such trends can be observed in the trace element signatures of the foraminiferal tests and can be used for interpreting climate, nutrient and sea water composition. Therefore the indicator stable isotopic composition as well as trace elements of the foraminiferal tests has the potential application in inferring the microhabitats of fossil foraminifera and the redox condition of the ambient environment.

Trace elements in Foraminifera are no longer just a curiosity but have become a unique tool to understand the past. Scientists all over the world are currently in the midst of a revolution in the investigation of trace elements in Foraminifera, and knowledge in this area is increasing rapidly. Culturing of live individuals has also played an important role in this proxy development, because the potential usefulness of trace elements can be verified directly by experimentation. Oceanographers broadly group elemental behaviour in the ocean according to the biogeochemical cycling of the elements in the ocean: [1] 'nutrient' proxies such as $\mathrm{Cd}, \mathrm{Ba}$ and $\mathrm{Zn}$ which provide information on seawater nutrient, carbon and carbonate levels. They show large and systematic variations in their seawater chemistry due to their involvement in biological cycling; [2] 'physical' proxies such as $\mathrm{Mg}$, Sr, F and $B$ isotopes, which dominantly reflect physical parameters such as temperature and pressure. The ratio of conservative elements to $\mathrm{Ca}$ is nearly fixed in seawater, and among the three groups, conservative elements have the longest oceanic residence times; [3] 'chemical' proxies such as Li, $\mathrm{U}$, $\mathrm{V}, \mathrm{Sr}$, and $\mathrm{Nd}$ isotopes, which provide diverse information on the history of ocean chemistry; and [4-6] 'diagenetic' proxies such as $\mathrm{Mn}$, which reflect secondary post-depositional processes. Particle reactive elements are rapidly cycled and have typically short oceanic residence times. Naturally, there is some overlap among these broad groups, but the divisions are a helpful way to view the toolbox of elemental proxies available to the paleoceanographer $[7,8]$.

\section{References}

1. Banerjee K, Senthilkumar B, Purvaja R and Ramesh R (2012) Sedimentation and trace metal distribution in selected locations of Sundarbans mangroves and Hooghly estuary, Northeast coast of India. Environ Geochem Health 34: 27-42.

2. Bhalla SN, Khare N, Shanmukha DH, Henriques PJ (2007) Foraminiferal studies in nearshore regions of western coast of India and Laccadives Islands: A review. Indian Journal of Marine Sciences. 36(4): 272-287.

3. Bradshaw JS, Environmental Parameters and Marsh Foraminifera. 13(1): 26-38. 


\section{International Journal of Paleobiology \& Paleontology}

4. Dey M, Ganguly D, Chowdhury C, Majumder N, Jana TK (2012) Intra-Annual Variation of Modern Foraminiferal Assemblage in a Tropical Mangrove Ecosystem in India. Wetlands 32: 813-826.

5. Ghosh A, Biswas S, Barman P (2014) Marsh Foraminiferal Assemblages in Relation to Vegetation in Sunderban, India. Journal Geological Society of India. 84: 657-667.

6. Mukhopadhyay SK, Biswas H, De TK, Jana TK (2006) Fluxes of nutrients from the tropical River Hooghly at the land-ocean boundary of Sunderbans, NE Coast of Bay of Bengal, India. 62(1-2): 9-21.

7. Nigam R, Kurtarkar SR, Saraswat R, Linshy VN, Rana SS (2008) Response of benthic foraminifera Rosalina leei to different temperature and salinity, under laboratory culture experiment. 88(4): 699-704.

8. Woodroffe SA, Horton BP, Larcombe P, Whittaker JE (2005) Intertidal mangrove foraminifera from the Central Great Barrier Reef Shelf, Australia: Implications for Sea-Level Reconstruction. Journal of Foraminiferal Research 35(3): 259-270. 